\title{
Salt intake in Eastern Saudi Arabia
}

A.M. Alkhunaizi, ${ }^{1}$ H.A. Al Jishi' ${ }^{2}$ and Z.A. Al Sadah ${ }^{2}$

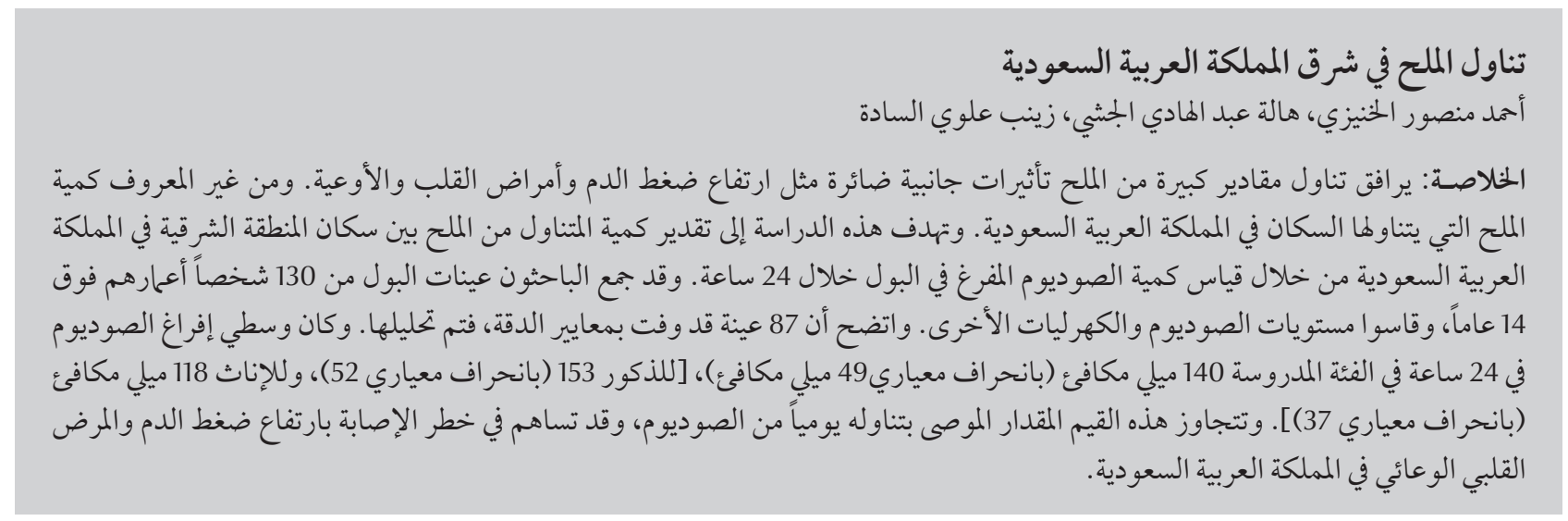

ABSTRACT High salt intake has been associated with adverse side-effects such as hypertension and cardiovascular disease. The amount of salt intake among the population of Saudi Arabia is not known. The objective of this study was to estimate the salt intake among residents of the Eastern region of Saudi Arabia by measuring 24-hour urinary sodium excretion. Urine samples were collected from 130 individuals aged over 14 years for measurement of levels of sodium and other electrolytes. A total of 87 samples met the criteria for accuracy and were analysed. Total mean 24-hour sodium excretion for the group was 140 (SD 49) mEq [153 (SD 52) mEq for males and 118 (SD 37) $\mathrm{mEq}$ for females]. These values exceed the recommended daily intake of sodium and may contribute to the risk of developing hypertension and cardiovascular disease in Saudi Arabia.

\section{Apport en sel dans l'est de l'Arabie saoudite}

RÉSUMÉ Un apport élevé en sel a été associé à des effets secondaires indésirables tels que l'hypertension et des maladies cardio-vasculaires. La quantité de sel consommée par la population d'Arabie saoudite n'est pas connue. L'objectif de la présente étude était d'estimer l'apport en sel chez des résidents de la région est d'Arabie saoudite en mesurant leur excrétion urinaire de sodium en 24 heures. Des échantillons d'urine ont été recueillis auprès de 130 personnes âgées de plus de 14 ans afin de mesurer les concentrations de sodium et d'autres électrolytes. Au total, 87 échantillons ont satisfait aux critères de précision et ont été analysés. L'excrétion de sodium moyenne totale en 24 heures pour le groupe était de $140 \mathrm{mEq}$ (E.T. 49) (153 mEq [E.T. 52] pour les hommes et $118 \mathrm{mEq}$ [E.T. 37] pour les femmes). Ces valeurs sont supérieures à celles recommandées pour l'apport en sodium quotidien et représentent un risque de survenue d'hypertension et de maladies cardiovasculaires dans la population saoudienne. 


\section{Introduction}

High levels of salt intake in the form of sodium chloride are associated with adverse events such as the development of hypertension, cardiovascular events and strokes [1-4]. Reducing dietary salt intake could substantially reduce cardiovascular events and strokes and may increase people's lifespan and reduce national health-care expenditures [5-9]. The World Health Organization (WHO) has recommended salt reduction as a top priority for tackling noncommunicable diseases and has considered this a public health target [10]. Similarly, the Institute of Medicine (IOM) in the United States has issued recommendations to decrease sodium intake [11].

There is a great variation in salt intake between different populations, ranging from $1 \mathrm{mEq}$ /day among the Yanomamo Indians in the Amazon valley in Brazil to $299 \mathrm{mEq} /$ day in some parts of China [12-15]. The amount of salt intake among the population of Saudi Arabia is not known. The aim of this study was to measure 24-hour urinary sodium excretion in order to estimate the sodium intake and to measure some other essential electrolytes among citizens in the Eastern region of Saudi Arabia.

\section{Methods}

\section{Sample}

A total of 130 citizens from Eastern Saudi Arabia above the age of 14 years were recruited. The participants included healthy volunteers, healthy potential kidney donors and patients who underwent work-up for nephrolithiasis.

\section{Data collection}

Sodium intake was estimated by measuring 24-hour urinary sodium excretion. Samples were collected between October and March for 4 consecutive years between 2009 and 2012. Due to the hot climate in this area during the summer months and the possibility of excessive sodium loss in sweat, the samples were collected during the season of temperate climate between October and March. The study was approved by the institutional review board at Saudi Aramco Medical Services Organization.

The participants were given clear instructions about urine collection for a total of 24 hours. All participants were instructed not to modify their diet during the study period. Patients with chronic kidney disease, those receiving diuretics and patients with gastrointestinal disorders were excluded. To guard against over- and under-collection, urinary creatinine was measured in all samples. A daily creatinine excretion of $20-25 \mathrm{mg} / \mathrm{kg}$ and $15-20 \mathrm{mg} / \mathrm{kg}$ lean body weight was expected for males and females respectively. Samples with a total creatinine excretion outside these ranges were rejected. In addition to urinary sodium, other electrolytes including potassium and magnesium were also measured.

Blood pressure (BP), weight, and body mass index (BMI) were determined for all participants. Casual (in office, resting) BP was measured using automatic oscillometric devices following the standardized National Joint Commission protocol [16]. The mean of $3 \mathrm{BP}$ measurements at 3 different encounters was recorded.

The electrolytes were measured by dry chemistry methods using Vitros 350 Chemistry System (Ortho Clinical Diagnostics).

\section{Data analysis}

The software Microsoft Excel 2010 and Graphpad Prism, version 2.0 were used for the statistical analysis. Data were expressed as mean values with standard deviation (SD). Pearson correlation coefficient $(r)$ was used to analyse the association between electrolytes excretion and the various variables of the study population. $P$-values of $<0.05$ were considered significant.

\section{Results}

The 24-hour urinary collection was performed on a total of 130 participants; 43 samples were excluded from the analysis due to incorrect collection. Analysis was performed on a total of 87 samples (54 from males and 33 from females). The mean age of the participants was 44 (SD 18), range $14-83$ years. The mean ages were 45 (SD 18) years and 41 (SD 17) years for males and females respectively.

Table 1 shows the demographic data of the participants and the measured electrolyte excretion in male and female participants. The sodium excretion of the male participants was particularly high $(153 \mathrm{mEq} /$ day $)$, and much higher than that of the female participants (118 mEq/day).

Correlations between 24-hour sodium excretion and age, BMI and systolic and diastolic BP are shown in Table 2. Among the male participants there was a negative correlation between sodium excretion and age, and a positive correlation with body weight. This did not reach statistical significance, however, for the female participants.

\section{Discussion}

The WHO recommends that all countries assess the sodium consumption of the population [17]. Most of the sodium in the diet is ingested in the form of sodium chloride. The WHO recommends an intake of no more than $5 \mathrm{~g}$ of sodium chloride or $2 \mathrm{~g}$ of sodium $(85 \mathrm{mEq})$ per day, while the IOM recommends that adults should not consume more than $2.3 \mathrm{~g}$ of sodium $(100 \mathrm{mEq})$ per day $[11,17]$. Based on these recommendations and due to the adverse health effects of dietary salt, many countries have adopted policies 


\begin{tabular}{|c|c|c|c|c|c|c|c|c|}
\hline \multirow[t]{3}{*}{ Sex } & \multirow{3}{*}{$\begin{array}{l}\text { No. of } \\
\text { people }\end{array}$} & \multicolumn{7}{|c|}{ Mean (SD) values } \\
\hline & & \multirow{2}{*}{$\begin{array}{c}\text { Age } \\
\text { (years) }\end{array}$} & \multirow{2}{*}{$\begin{array}{c}\text { BMI } \\
\left(\mathrm{kg} / \mathrm{m}^{2}\right)\end{array}$} & \multicolumn{2}{|c|}{ BP (mmHg) } & \multicolumn{3}{|c|}{ Electrolytes } \\
\hline & & & & Systolic & Diastolic & $\begin{array}{l}\mathrm{Na}^{+} \\
(\mathrm{mEq})\end{array}$ & $\begin{array}{c}\mathrm{K}^{+} \\
(\mathrm{mEq})\end{array}$ & $\begin{array}{l}\mathrm{Mg}^{2+} \\
(\mathrm{mg})\end{array}$ \\
\hline Total & 87 & $44(18)$ & $27(5)$ & 129 (15) & $75(8)$ & $140(49)$ & $56(22)$ & $81(37)$ \\
\hline Male & 54 & $45(18)$ & $28(5)$ & $132(15)$ & $75(8)$ & $153(52)$ & $60(24)$ & $88(41)$ \\
\hline Females & 33 & $41(17)$ & $27(6)$ & $125(14)$ & $74(6)$ & $118(37)$ & $50(16)$ & $70(25)$ \\
\hline
\end{tabular}

$B M I=$ body mass index $; B P=$ blood pressure $; S=$ standard deviation.

$\mathrm{Na}^{+}=$sodium $; \mathrm{K}^{+}=$potassium $; \mathrm{Mg}^{2+}=$ magnesium .

to regulate salt consumption through educating people to reduce the use of salt in cooking and by persuading the food industry to minimize the use of salt in their products. Estimating salt intake by measuring salt excretion is an essential step towards formulating these policies. There are different methods for estimating sodium consumption, including 24-hour urinary collection, casual spot urine collection and timed spot urine collection. Among these methods, the first is the most accurate. In an earlier report in 2007, the WHO suggested that as few as 100 individuals from a representative sample, with each participant carrying out a single 24-hour urine collection, would be sufficient to provide an estimate of the sodium intake of a population [18].

The daily intake of sodium has not been officially documented in the Saudi population. As a result of lifestyle changes in the country, diabetes and hypertension have reached epidemic levels [19]. The hot climate during the summer months in Eastern Saudi Arabia may result in large losses of water and salt in the sweat. To avoid any substantial sodium loss in the sweat, we conducted the study during the season of moderate climate between October and March. The main bulk of the study sample was healthy adult individuals. Sodium intake, as reflected in the mean 24hour sodium excretion rate, was 140 (SD 49) $\mathrm{mEq}$, which is higher than recommended by both WHO and $\operatorname{IOM}[10,11]$. This was true for both males and females, with mean values of 153 (SD 52) mEq and 118 (SD 37) $\mathrm{mEq}$ respectively. There was a negative correlation between sodium excretion and age, and a positive

\begin{tabular}{|c|c|c|c|}
\hline \multicolumn{4}{|c|}{$\begin{array}{l}\text { Table } 2 \text { Correlation between } 24 \text {-hour urinary sodium excretion and several } \\
\text { variables among male and female participants }\end{array}$} \\
\hline Sex/variable & $r$ & $95 \% \mathrm{Cl}$ & $P$-value \\
\hline \multicolumn{4}{|l|}{ Males } \\
\hline Age & -0.33 & -0.55 to -0.07 & 0.015 \\
\hline BMI & 0.27 & -0.01 to -0.50 & 0.05 \\
\hline Mean SBP & 0.01 & -0.26 to -0.28 & 0.94 \\
\hline Mean DBP & 0.19 & -0.08 to -0.44 & 0.167 \\
\hline \multicolumn{4}{|l|}{ Females } \\
\hline Age & -0.01 & -0.35 to -0.34 & 0.96 \\
\hline BMI & -0.07 & -0.41 to -0.28 & 0.68 \\
\hline Mean SBP & -0.08 & -0.41 to -0.27 & 0.66 \\
\hline Mean DBP & 0.05 & 0.30 to -0.39 & 0.78 \\
\hline
\end{tabular}

$r=$ correlation coefficient $; C I=$ confidence interval; $B M I=$ body mass index; $S B P=$ systolic blood pressure; $D B P$ = diastolic blood pressure. correlation with BMI among the male participants, most likely as a result of the overall high calorie intake among the young and overweight individuals. This was not observed in the female participants, probably due to the small sample size. We did not find a correlation between sodium excretion and either systolic or diastolic blood pressure. This may be attributed to the relatively young age of the cohort.

Besides sodium intake, low potassium intake has also been associated with the development of cardiovascular disease and stroke [20]. Adequate potassium intake is recommended to counteract the adverse effects of sodium chloride. The IOM recommended a daily potassium intake of $4.7 \mathrm{~g}(120 \mathrm{mEq})$ for adults [21]. Similar to sodium, potassium homeostasis is mainly regulated by the kidneys. The amount of potassium loss in the sweat and through the gastrointestinal tract is minimal under normal conditions. Therefore, and similar to sodium, urinary excretion of potassium is considered a surrogate for potassium intake. Our data showing a 24-hour mean excretion of 56 (SD 22) $\mathrm{mEq}$ indicated that potassium intake was low in the total group and in both sexes of the sample population $[60(\mathrm{SD} 24) \mathrm{mEq}$ and 50 (SD 16) $\mathrm{mEq}$ in males and females respectively]. This, in addition to high sodium intake, puts our population at an increased risk for the development of hypertension, cardiovascular disease and stroke. 
Magnesium is another mineral that has vital biological functions. The recommended dietary allowances of magnesium are $320 \mathrm{mg}$ and $420 \mathrm{mg}$ for adult women and men respectively [22]. Balance studies have shown that the net magnesium absorption is around $50 \%$, with a range from $10 \%-65 \%$ of the total intake depending on the diet $[23,24]$. In the absence of diarrhoea, most of the absorbed magnesium will be excreted in the kidneys. Based on this, our data of 24-hour magnesium excretion [mean 81 (SD 37) mg] may not necessarily reflect magnesium intake, and we can only speculate that the intake of magnesium in our cohort is lower than what is recommended by the IOM. However, that can only be confirmed by quantification of the actual content of magnesium in the diet.

This study gives insight into the amount of sodium intake in this region of Saudi Arabia, and suggests that measures should be adopted to improve the dietary habits of the population with the hope to decrease the associated adverse health effects of high salt intake. The results of this study could very well be extrapolated to other neighbouring regions where people share similar cultures and dietary habits.

\section{Acknowledgements}

The authors acknowledge the use of Saudi Aramco Medical Services Organization (SAMSO) facilities for research data used in this article. Opinions expressed in this article are those of the authors and not necessarily of SAMSO. The authors also thank Mrs Fatimah A. Alkhunaizi from the Krieger School of Arts and Sciences at the Johns Hopkins University, Baltimore, USA for reviewing the manuscript and for her valuable comments.

Funding: The study was funded by Saudi Aramco Medical Services Organization, Saudi Arabia.

Competing interests: None declared.

\section{References}

1. Conlin PR. Eat your fruits and vegetables but hold the salt. Circulation, 2007, 116:1530-1531.

2. He J et al. Long-term effects of weight loss and dietary sodium reduction on incidence of hypertension. Hypertension, 2000, 35:544-549.

3. Cook NR et al. Long term effects of dietary sodium reduction on cardiovascular disease outcomes: observational follow-up of the trials of hypertension prevention (TOHP). British Medical Journal, 2007, 334:885-888.

4. He FJ, MacGregor GA, McCarron DA. Salt intake and cardiovascular disease. Nephrology, Dialysis, Transplantation, 2008, 23:3382-3384.

5. Bibbins-Domingo K et al. Projected effect of dietary salt reductions on future cardiovascular disease. New England Journal of Medicine, 2010, 362:590-599.

6. He FJ, MacGregor GA. Effect of longer-term modest salt reduction on blood pressure. Cochrane Database of Systematic Reviews, 2004, (3):CD004937.

7. He FJ, MacGregor GA. Salt reduction lowers cardiovascular risk: meta-analysis of outcome trials. Lancet, 2011, 378:380382.

8. Strazzullo P et al. Salt intake, stroke, and cardiovascular disease: meta-analysis of prospective studies. British Medical Journal, 2009, 339:b4567.

9. He FJ, MacGregor GA. How far should salt intake be reduced? Hypertension, 2003, 42:1093-1099.

10. Beaglehole R et al.; Lancet NCD Action Group; NCD Alliance. Priority actions for the non-communicable disease crisis. Lancet, 2011, 377:1438-1447.

11. Institute of Medicine of the National Academies. Strategies to reduce sodium intake in the United States. Washington DC, National Academy Press, 2010.

12. Oliver WJ, Cohen EL, Neel JV. Blood pressure, sodium intake, and sodium related hormones in the Yanomamo Indians, a "no-salt" culture. Circulation, 1975, 52:146-151.

13. Elliott $\mathrm{P}$ et al.; Intersalt Cooperative Research Group. Intersalt revisited: further analyses of 24 hour sodium excretion and blood pressure within and across populations. British Medical Journal, 1996, 312:1249-1253.
14. Stamler J et al.; INTERMAP Research Group. INTERMAP: background, aims, design, methods, and descriptive statistics (nondietary). Journal of Human Hypertension, 2003, 17:591-608.

15. Rose G, Stamler J; INTERSALT Co-operative Research Group. The INTERSALT study: background, methods and main results. Journal of Human Hypertension, 1989, 3:283-288.

16. Chobanian AV et al.; National High Blood Pressure Education Program Coordinating Committee. Seventh report of the Joint National Committee on Prevention, Detection, Evaluation, and Treatment of High Blood Pressure. Hypertension, 2003, 42:1206-1252.

17. Strategies to monitor and evaluate population sodium consumption and sources of sodium in the diet. Report of a joint technical meeting convened by WHO and the Government of Canada. Geneva, World Health Organization, 2010.

18. Salt intakes around the world: implications for public health. Geneva, World Health Organization, 2007.

19. Al-Khader AA. Impact of diabetes in renal diseases in Saudi Arabia. Nephrology, Dialysis, Transplantation, 2001, 16:21322135.

20. O'Donnell MJ et al. Urinary sodium and potassium excretion and risk of cardiovascular events. Journal of the American Medical Association, 2011, 306:2229-2238.

21. Institute of Medicine of the National Academies. Dietary reference intakes for water, potassium, sodium, chloride, and sulfate. Washington DC, National Academy Press, 2005.

22. Institute of Medicine of the National Academies. Dietary reference intakes for calcium, phosphorus, magnesium, vitamin D, and fluoride. Washington DC, National Academy Press, 1997.

23. Schwartz R, Spencer H, Welsh JJ. Magnesium absorption in human subjects from leafy vegetables, intrinsically labeled with stable 26Mg. American Journal of Clinical Nutrition, 1984, 39:571-576.

24. Fine $\mathrm{KD}$ et al. Intestinal absorption of magnesium from food and supplements. Journal of Clinical Investigation, 1991, 88:396-402. 